\title{
Serum TGF- $\beta 1$ and SMAD3 levels are closely associated with coronary artery disease
}

\author{
Can Chen ${ }^{1,2}$, Wei Lei ${ }^{2}$, Wenjiang Chen², Jianfeng Zhong ${ }^{2}$, Xiaoxin Gao², Bo Li ${ }^{2}$, Huailong Wang ${ }^{2}$ \\ and Congxin Huang ${ }^{1 *}$
}

\begin{abstract}
Background: Coronary artery disease (CAD) is one of the most common diseases leading to mortality and morbidity worldwide. There is considerable debate on whether serum transforming growth factor $\beta 1$ (TGF- $\beta 1$ ) levels are associated with long-term major adverse cardiovascular events in patients with CAD, and to date, no study has specifically addressed levels in patients with different degrees of CAD severity.

Methods: Serum TGF- $\beta 1$ and mothers against decapentaplegic homolog 3 (SMAD3) concentrations were evaluated in 279 patients with CAD and 268 controls without CAD. The clinical and biochemical characteristics of all subjects were also determined and analyzed.

Results: TGF- $\beta 1$ and SMAD3 concentrations in CAD patients were significantly higher than those in the controls. The serum TGF- $\beta 1$ level in acute myocardial infarction (AMI) was significantly higher than that in both stable angina pectoris (SAP) and unstable angina pectoris (UAP) $(p<0.05)$, while there was no marked difference between levels in SAP and UAP $(p>0.05)$. SMAD3 levels showed no obvious difference among AMI, SAP, and UAP. TGF- $\beta 1$ and SMAD3 are potential biomarkers for CAD, and may be more accurate than $L p a$, ApoA1, uric acid, BUN, or triglycerides (TG).
\end{abstract}

Conclusions: Serum TGF- $\beta 1$ and SMAD3 levels are closely associated with CAD, and may become useful biomarkers for diagnosis and risk stratification.

Keywords: Coronary artery disease, TGF- $\beta 1$, SMAD3 protein, Human, Biomarkers

\section{Background}

Coronary artery disease (CAD) is one of the leading causes of mortality and morbidity worldwide, especially in many developed countries [1,2]. According to the World Health Organization, it is predicted that 23.6 million deaths per year will be because of cardiovascular diseases by 2030 [3]. CAD, with a complex etiology, is considered to be the result of an interaction between genetic and environmental factors [4-6]. In the past decades, many contributing factors including smoking, hypertension, diabetes mellitus (DM), atherosclerosis, obesity, and diet have been established, but the exact etiology underlying CAD remains obscure. Increasing

\footnotetext{
* Correspondence: huangcongxin@vip.163.com

${ }^{1}$ Department of Cardiovascular Medicine, Renmin Hospital of Wuhan University, Wuhan 430060, China

Full list of author information is available at the end of the article
}

evidence suggests that inflammation plays an important role in the pathogenesis of CAD $[7,8]$.

A number of inflammatory cytokines mediate adverse cardiovascular events in patients with CAD, and transforming growth factor- $\beta 1$ (TGF- $\beta 1$ ) has garnered particular attention because of its multiple roles in important pathological changes such as enhancement of macrophage and fibroblast chemotaxis, stimulation of extracellular matrix (ECM) synthesis, and vascular cell proliferation abnormalities $[9,10]$. Although it has been known that TGF$\beta 1$ activates several pathways, including the extracellularregulated kinase pathway, the nuclear factor- $\kappa B$ pathway, and the phosphatidylinositol-3-kinase pathway [11,12], its main signaling mechanism is linked to the mothers against decapentaplegic homolog 3 (SMAD3) family [13]. TGF- $\beta 1$ binds to its type I receptors and forms a heteromeric complex with the type II receptor, which subsequently results in phosphorylation and activation of the 
TGF- $\beta 1$ downstream signaling molecules SMAD2 and SMAD3. Activated SMAD2 or SMAD3 heterodimerizes with SMAD4 and then introduces the above complex into the nucleus, where it regulates the expression of its target gene $[14,15]$. TGF- $\beta 1 /$ SMAD3-dependent pathways play a pivotal role in mediating different biological effects of TGF- $\beta 1$ such as cell proliferation, immune suppression, and inflammation [12,16-18]. In the cardiovascular system, myocardial TGF- $\beta 1$ expression is markedly activated in patients with hypertrophic or dilated cardiomyopathy, and in experimental models of myocardial hypertrophy and myocardial infarction [19]. Other studies suggest that TGF- $\beta$ signaling may be crucial for repression of inflammatory gene expression in healing infarcts mediated by an inflammatory infiltrate [20]. TGF- $\beta 1$ is crucial in the pathogenesis of infarct healing, cardiac remodeling, and interstitial fibrosis. There have been few clinical investigations of TGF- $\beta 1 /$ SMAD3 signals in large patient groups. There is considerable debate over any correlation of TGF- $\beta 1$ levels with major adverse cardiovascular events in patients with CAD. In particular, no study has specifically addressed patients with different degrees of CAD [9].

We collected serum samples from 279 patients with CAD and from 297 controls, and assessed for any association between serum TGF- $\beta 1 /$ SMAD3 levels and the presence and severity of CAD. We evaluated the potential clinical application of measurements of these cytokines for CAD diagnosis, comparing their utility with the currently used biochemical indicators.

\section{Methods}

\section{Study population}

Written informed consent was obtained from the population involved in this study and the study protocol was approved by the Ethics Committee of Affiliated Hospital of Guangdong Medical College.

A total of 279 patients who were referred for coronary angiography by their attending physicians from May to August 2013, and who were found to have at least 50\% stenosis in at least one coronary artery, were included. Their ages were about 69.30 years. The 268 controls were consecutive subjects undergoing routine medical examinations at the Physical Examination Center. Those who had any clinical manifestations or a medical history of heart disorders, a family history of coronary artery disease, or abnormal ECG were excluded. Exclusion criteria also included acute or chronic infections or inflammatory diseases, severe hepatic or renal dysfunction, malignant tumors, or hematologic disorders. The CAD group was divided into three subgroups: acute myocardial infarction (AMI), unstable angina pectoris (UAP), and stable angina pectoris (SAP).

\section{Physiological evaluation and blood collection}

All study participants underwent a standard clinical examination. Body mass index (BMI) was calculated as the individual's body mass divided by the square of their height. Smoking was defined as having smoked for at least 1 year currently. Hypertension was defined as a systolic blood pressure of $\geq 140 \mathrm{~mm} \mathrm{Hg}$ or use of antihypertensive therapy. Diabetes was diagnosed according to nonfasting glucose levels $\geq 11.1 \mathrm{mmol} / \mathrm{L}$.

Approximately $2 \mathrm{~mL}$ of venous blood was collected from each subject, and then kept in tubes without preservatives at $4^{\circ} \mathrm{C}$ overnight. Serum aliquots were obtained after centrifugation at $1000 \mathrm{~g}$ for $40 \mathrm{~min}$ at $4^{\circ} \mathrm{C}$.

\section{Coronary angiography}

All coronary angiographies were performed using standard technique. Significant CAD was considered to be present if there was an internal luminal stenosis $\geq$ $50 \%$ in the left main coronary artery, right coronary artery, and/or their major branches. The degree of coronary atherosclerosis was further categorized according to the number of coronary vessels with significant

Table 1 Clinical and biochemical characteristics of the study population

\begin{tabular}{llll}
\hline Variables & CAD & Control & p \\
\hline Sex (M/F) & $168 / 111$ & $180 / 88$ & 0.0913 \\
Age (years) & $69.30 \pm 0.7049$ & $63.73 \pm 0.6952$ & $<0.0001$ \\
BMI (kg/m²) & $23.18 \pm 0.1337$ & $21.04 \pm 0.08991$ & $<0.0001$ \\
Smoke (\%) & 12.19 & 5.60 & 0.007 \\
Hypertension (\%) & 26.16 & 18.66 & 0.0355 \\
DM (\%) & 25.81 & 15.30 & 0.0024 \\
AF (\%) & 8.60 & 0 & $<0.0001$ \\
Stroke (\%) & 7.17 & 1.12 & 0.0004 \\
High TC (\%) & 10.39 & 8.21 & 0.3796 \\
High TG (\%) & 13.62 & 7.09 & 0.0125 \\
Low HDL (\%) & 28.32 & 38.06 & 0.0155 \\
High LDL (\%) & 10.04 & 9.33 & 0.7798 \\
Lp(a) (mg/l) & $265.4 \pm 12.43$ & $215.9 \pm 11.11$ & 0.0033 \\
BUN (mmol/l) & $5.898 \pm 0.1978$ & $5.075 \pm 0.1675$ & 0.0016 \\
SUA ( $\mu$ mol/l) & $340.6 \pm 6.018$ & $280.6 \pm 6.629$ & $<0.0001$ \\
Glu (mmol/l) & $6.549 \pm 0.1418$ & $6.011 \pm 0.1231$ & 0.0046 \\
CHOL (mmol/l) & $4.785 \pm 0.07130$ & $4.821 \pm 0.2581$ & 0.8885 \\
TG (mmol/l) & $1.567 \pm 0.07598$ & $1.341 \pm 0.04895$ & 0.0148 \\
HDL (mmol/l) & $1.256 \pm 0.0214$ & $1.242 \pm 0.02509$ & 0.6613 \\
LDL (mmol/l) & $2.854 \pm 0.05867$ & $4.190 \pm 1.467$ & 0.3377 \\
ApoA1 (g/l) & $1.339 \pm 0.02123$ & $1.262 \pm 0.02484$ & 0.0187 \\
ApoB (g/l) & $0.9414 \pm 0.01682$ & $0.8810 \pm 0.01690$ & 0.0117 \\
\hline
\end{tabular}


stenoses as 1-, 2-, or $\geq 3$-vessel disease. All catheterizations and imaging analyses were performed by two experienced interventional cardiologists who were unaware of the patients' clinical data.

\section{Biochemical assay}

Fasting blood samples were obtained and prepared for the biochemical assay of clinical indices associated with CAD diagnosis, including lipoprotein (a) (Lp(a)), blood urea nitrogen (BUN), uric acid (SUA), blood glucose (Glu), total cholesterol (CHOL), high-density lipoprotein (HDL), low-density lipoprotein (LDL), triglycerides (TG), apolipoprotein A1 (ApoA1), and apolipoprotein B (ApoB).

\section{Measurements of TGF- $\beta 1$ and Smad3 levels}

Determination of serum active TGF- $\beta 1$ and SMAD3 concentration was performed by ELISA using the ELISA-Quantikine kit (R\&D Systems, Minneapolis, MN, USA) according to the manufacturer's instructions. The detection range of the ELISA used to measure TGF- $\beta 1$ was $100-1200 \mathrm{ng} / \mathrm{L}$, and the detection limit of SMAD3 was $2.5-30 \mathrm{pg} / \mathrm{mL}$. Their accuracy was expressed in the correlation coefficient, which was required to be greater than 0.9999 .

\section{Statistical analysis}

Categorical and continuous variables were expressed as percentiles and mean \pm standard error of mean (SEM), respectively. Differences among groups were assessed using the chi-squared or analysis of variance tests, followed by post-hoc analysis (Bonferroni's correction) for comparison among groups. The association between serum TGF- $\beta 1$ or SMAD3 and CAD or its risk factors was estimated using a multivariate logistic regression model.

\section{Results}

Patient characteristics

The main demographic and clinical characteristics of all the studied subjects are summarized in Table 1.

There were significant differences between CAD and control groups in important risk factors including age,

Table 2 Clinical and biochemical characteristics of the study population with differing CAD severity

\begin{tabular}{|c|c|c|c|c|}
\hline \multirow[t]{2}{*}{ Variables } & \multicolumn{3}{|l|}{ CAD } & \multirow[t]{2}{*}{ Control } \\
\hline & $\overline{\mathrm{AMI}}$ & SAP & UAP & \\
\hline $\operatorname{Sex}(M / F)$ & $30 / 21$ & $92 / 69(\mathrm{M} / \mathrm{F})$ & $46 / 21(\mathrm{M} / \mathrm{F})$ & 180/88(M/F) \\
\hline Age (years) & $67.86 \pm 1.823$ & $69.97 \pm 0.8970$ & $68.81 \pm 1.438$ & $63.73 \pm 0.69^{* * *}$ \\
\hline BMI $\left(\mathrm{kg} / \mathrm{m}^{2}\right)$ & $22.72 \pm 0.2705$ & $23.08 \pm 0.1743 \#$ & $23.78 \pm 0.2934 \#$ & $21.04 \pm 0.089^{* * *}$ \\
\hline Smokers (\%) & 15.69 & 11.18 & 11.94 & $5.60^{*}$ \\
\hline Hypertension (\%) & 31.37 & 21.12 & 10.35 & $18.66^{* * *}$ \\
\hline DM (\%) & 27.45 & 27.33 & 20.90 & $15.30^{* *}$ \\
\hline AF (\%) & 13.72 & 3.73\# & 1.49\# & $0^{* * *}$ \\
\hline Stroke (\%) & 7.84 & 5.59 & 10.45 & $1.12^{* * *}$ \\
\hline High TC (\%) & 19.61 & 8.07 & 8.96 & 8.21 \\
\hline High TG (\%) & 17.68 & 11.80 & 14.92 & $7.09^{*}$ \\
\hline Low HDL (\%) & 15.69 & 30.43 & 32.84 & $38.06^{* *}$ \\
\hline High LDL (\%) & 13.72 & 9.32 & 8.96 & 9.33 \\
\hline Lp(a) (mg/l) & $292.5 \pm 33.46$ & $244.4 \pm 14.90$ & $295.3 \pm 27.06$ & $215.9 \pm 11.11^{* *}$ \\
\hline BUN (mmol/l) & $6.424 \pm 0.5315$ & $5.628 \pm 0.2592$ & $6.147 \pm 0.3538$ & $5.075 \pm 0.167^{* *}$ \\
\hline SUA ( $\mu \mathrm{mol} / \mathrm{l})$ & $364.4 \pm 11.62$ & $328.2 \pm 8.385 \#$ & $352.2 \pm 11.56 \#$ & $280.6 \pm 6.629^{* * *}$ \\
\hline Glu (mmol/l) & $6.555 \pm 0.3058$ & $6.658 \pm 0.1950$ & $6.281 \pm 0.2754$ & $6.011 \pm 0.1231^{*}$ \\
\hline $\mathrm{CHOL}(\mathrm{mmol} / \mathrm{l})$ & $5.190 \pm 0.1761$ & $4.695 \pm 0.09342 \#$ & $4.690 \pm 0.1346 \#$ & $4.821 \pm 0.2581$ \\
\hline TG $(\mathrm{mmol} / \mathrm{l})$ & $1.624 \pm 0.1808$ & $1.528 \pm 0.1039$ & $1.619 \pm 0.1391$ & $1.341 \pm 0.04895$ \\
\hline $\mathrm{HDL}(\mathrm{mmol} / \mathrm{l})$ & $1.322 \pm 0.04794$ & $1.240 \pm 0.02690$ & $1.246 \pm 0.04980$ & $1.242 \pm 0.02509$ \\
\hline LDL (mmol/l) & $3.134 \pm 0.1226$ & $2.798 \pm 0.07992$ & $2.773 \pm 0.1157$ & $4.190 \pm 1.467$ \\
\hline ApoA1 (g/l) & $1.449 \pm 0.05356$ & $1.308 \pm 0.02764 \#$ & $1.329 \pm 0.04026 \#$ & $1.262 \pm 0.02484^{* *}$ \\
\hline ApoB (g/l) & $1.003 \pm 0.04239$ & $0.9385 \pm 0.0322$ & $0.9414 \pm 0.0168$ & $0.8810 \pm 0.01690^{*}$ \\
\hline
\end{tabular}

Date are means \pm SEM or $n(\%)$

$\# p<0.05$ vs SAP or UAP and ${ }^{*} p<0.05,{ }^{* *} p<0.01,{ }^{* * *} p<0.001$ vs Control. 


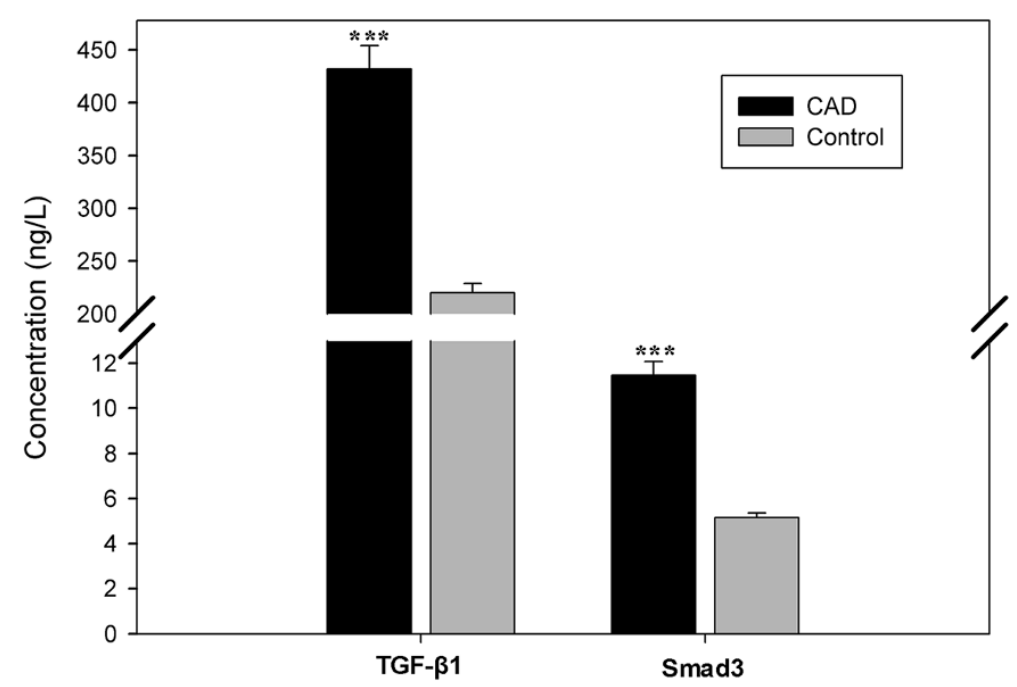

Figure 1 Serum TGF- $\beta 1$ and SMAD3 levels from CAD patients, ${ }^{* * *} p<0.0001,{ }^{*} p<0.05$.

BMI, smoking, hypertension, DM, atrial fibrillation (AF), stroke, TG, HDL, Lp(a), BUN, uric acid, ApoA1, and ApoB. CAD patients were divided into three subgroups by pathological types: AMI, SAP, and UAP (Table 2). The statistical analysis revealed that the risk factors of CAD mentioned above were significantly higher than in the controls, and, additionally, several indices, including BMI, AF, uric acid, total cholesterol, and ApoA1 showed significant differences among the three subgroups. Different levels of total cholesterol were found in acute myocardial infarction and angina pectoris patients, but not in CAD and control subjects.

\section{TGF- $\beta 1$ and SMAD3 levels in CAD patients}

TGF- $\beta 1$ and SMAD3 levels were both increased significantly in the CAD group compared with the controls $(\mathrm{p}<0.0001)$ (Figure 1). Serum TGF- $\beta 1$ and SMAD3 levels in the AMI, SAP, and UAP subgroups were all higher than in the control group $(\mathrm{p}<0.0001)$ (Figure 1$)$, suggesting that the two cytokines were related to CAD pathogenesis.

Comparing among the three subgroups of CAD subjects, serum TGF- $\beta 1$ levels in AMI were significantly higher than those in both SAP and UAP $(\mathrm{p}<0.05)$, while there was no marked difference between those in SAP

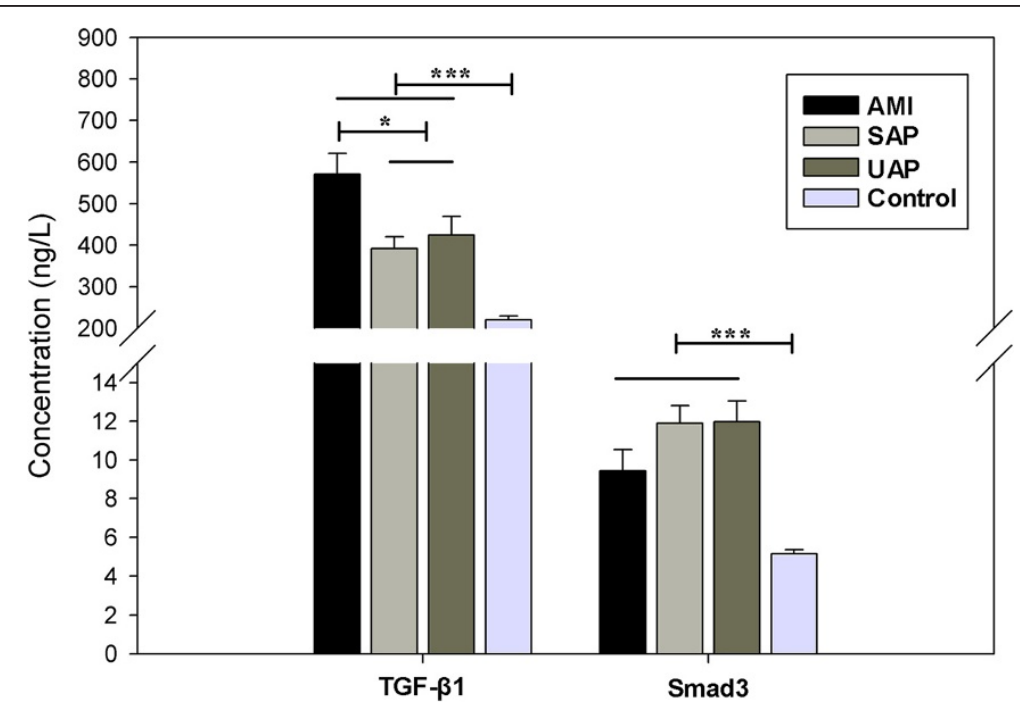

Figure 2 Serum TGF- $\beta 1$ and SMAD3 levels from patients with different CAD severity, ${ }^{* * *} p<0.0001,{ }^{*} p<0.05$. 
and UAP $(\mathrm{p}>0.05)$ (Figure 2). However, SMAD3 levels were not significantly different among AMI, SAP, and UAP subgroups, suggesting that TGF- $\beta 1$ may regulate the progression from angina pectoris to AMI.

\section{Correlation of TGF- $\beta 1$ and SMAD3 levels with CAD occurrence and its risk factors}

To explain a potential mechanism of TGF- $\beta 1$ and SMAD3, we evaluated their relationship with CAD and its risk factors including $\mathrm{Lp}(\mathrm{a}), \mathrm{BUN}$, creatinine, uric acid, blood glucose, total cholesterol, TG, HDL, LDL, ApoA1, and ApoB. There was a very significant correlation between CAD and concentration of TGF- $\beta 1$ and SMAD3 $(\mathrm{p}<0.0001)$. Among the other biochemical indices [21], TGF- $\beta 1$ significantly correlated with $\operatorname{Lp}(a)(p<0.0203)$ and uric acid $(\mathrm{p}<0.0001)$, respectively, and SMAD3 correlated very significantly with blood glucose $(\mathrm{p}<0.0001)$ (Figure 3).

\section{TGF- $\beta 1$ and SMAD3 as biomarkers for CAD}

Far higher TGF- $\beta 1$ and SMAD3 concentrations occurred in CAD patients (TGF- $\beta 1$ : $432.2 \pm 22.12 \mathrm{ng} / \mathrm{L}$; SMAD3: $11.47 \pm 0.6161 \mathrm{ng} / \mathrm{L}$ ) compared with controls (TGF- $\beta 1$ : $220.1 \pm 8.831 \mathrm{ng} / \mathrm{L} ;$ SMAD3: $5.157 \pm 0.1965 \mathrm{ng} / \mathrm{L})$. The area under the Receiver operating characteristic curves $\left(\mathrm{AUC}_{\mathrm{ROC}}\right)$ indicated that both TGF- $\beta 1\left(\mathrm{AUC}_{\mathrm{ROC}}\right.$ : 0.678, 95\% confidence interval [CI]: 0.633-0.723) and SMAD3 (AUC $_{\text {ROC }}: 0.715,95 \%$ CI: $0.672-0.758$ ) were the more potent biomarkers for CAD, compared with $\mathrm{Lpa}\left(\mathrm{AUC}_{\mathrm{ROC}}\right.$ : 0.574, 95\% CI: 0.525-0.623), ApoA1 (AUC ROC: 0.561, 95\% CI: $0.512-0.609$ ), uric acid (AUC $\mathrm{AOC}_{\mathrm{ROC}}$ 0.663, 95\% CI: 0.617-0.710), BUN (AUC ROC: 0.581, 95\% CI: 0.533-0.630),

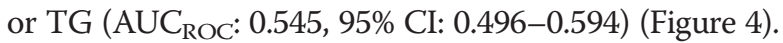

\section{Discussion}

TGF- $\beta 1$ is a multifunctional peptide that controls proliferation, differentiation, and other functions in many cell types, and it has dual regulation roles in immune response and cellular development. TGF- $\beta 1$ acts synergistically with TGF $\alpha$ in inducing transformation. It also acts as a negative autocrine growth factor. Dysregulation of TGF- $\beta 1$ activation and signaling may result in apoptosis. For example, TGF- $\beta 1$ inhibits cancer cell growth at the early stage of tumor formation, and promotes the cancer development in the late phase [22].

Previous studies have shown plasma TGF- $\beta 1$ levels to be reduced in patients with advanced atherosclerosis and angiographically proven CAD. The levels of TGF- $\beta 1$ were thought to be inversely related to the development and severity of coronary disease [23-27]. By contrast, Border and Ruoslahti found that TGF- $\beta 1$ could enhance atherogenesis by mediating excessive ECM deposition [28]. Another recent study revealed that a high plasma level of TGF- $\beta$ had a significantly strong prognosis in

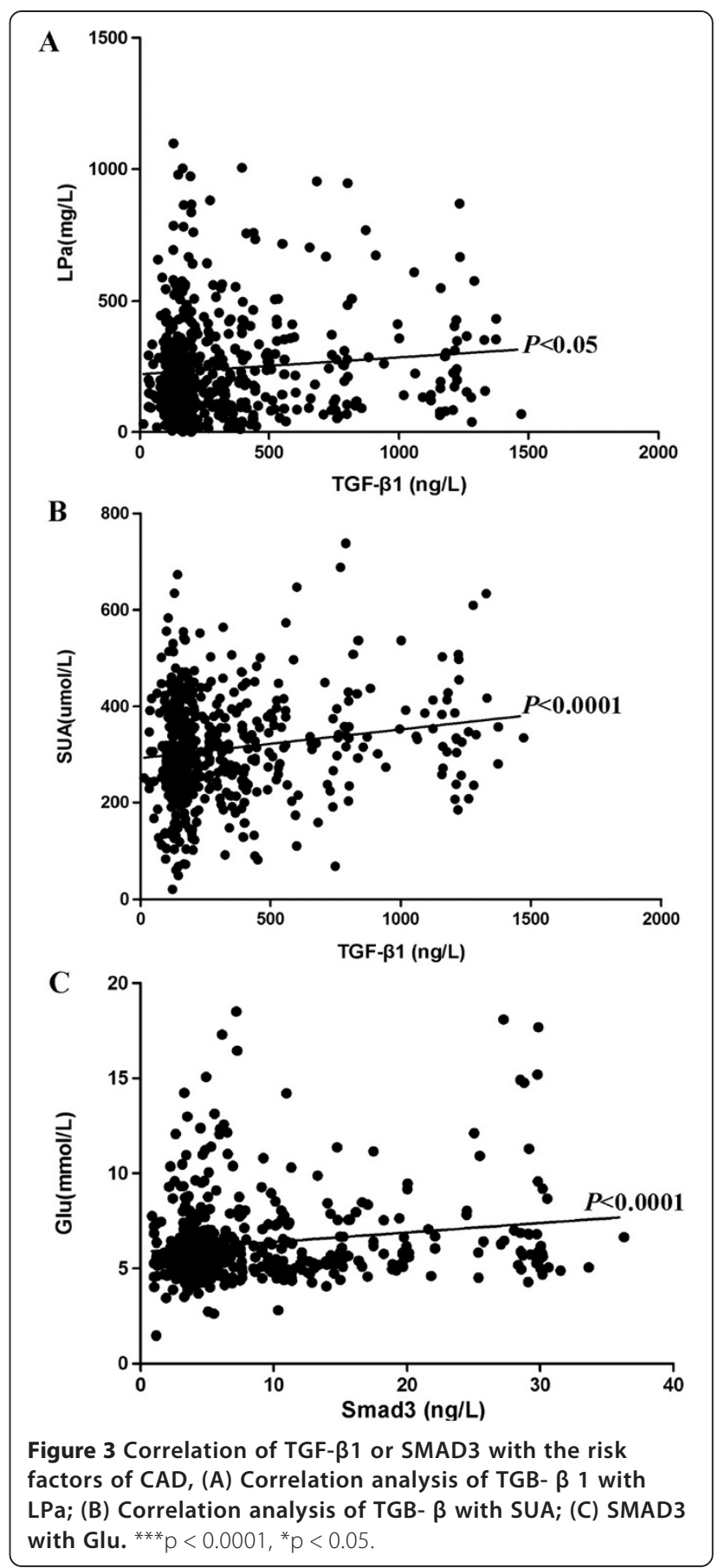

terms of survival without cardiovascular events and survival without coronary interventions compared with the low TGF- $\beta$ group (both $\mathrm{p}<0.05$ ), suggesting that plasma TGF- $\beta$ may potentially have great prognostic value in patients with CAD [29]. Schaan et al maintained that serum TGF- $\beta 1$ was not associated with CAD occurrence after clinical and laboratory evaluation of TGF- $\beta 1$ in patients with CAD or DM [9]. However, they sampled 


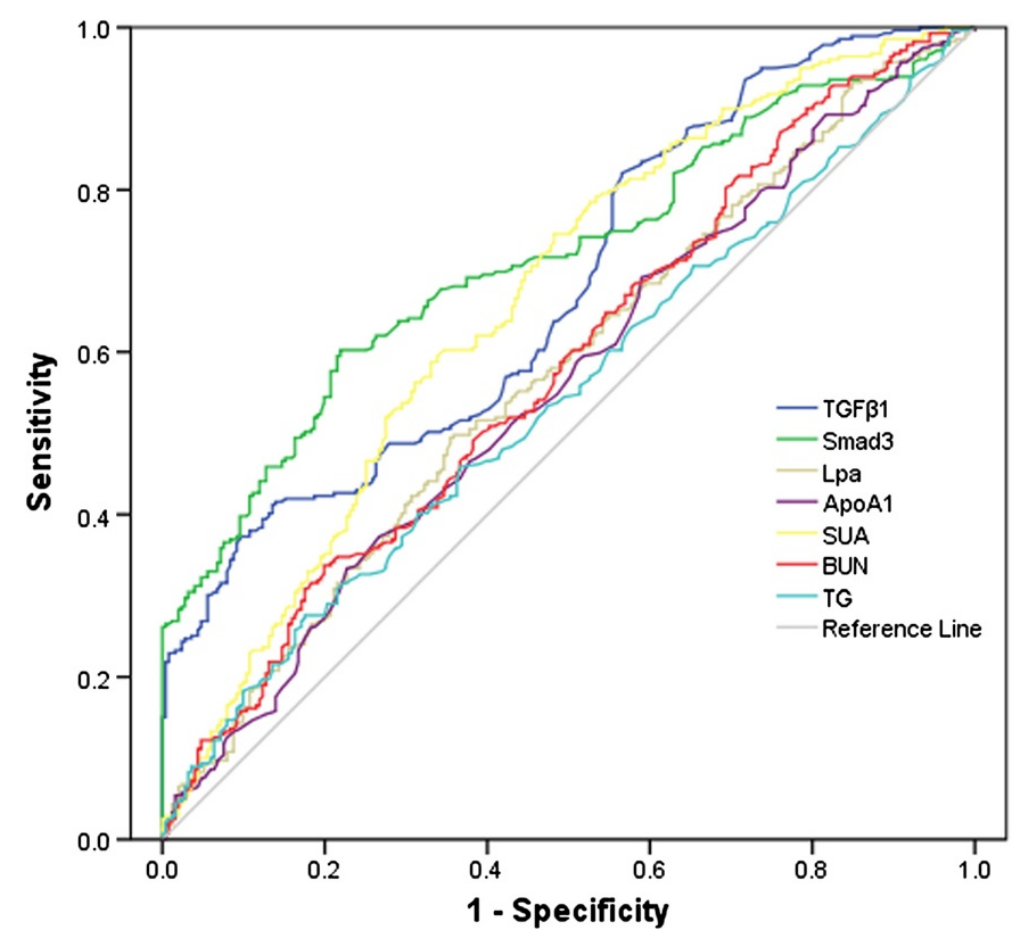

Figure 4 Receiver operating characteristic (ROC) curves for TGF- $\beta 1$ and SMAD3. The area under the curve of TGF- $\beta 1$ was 0.678 (95\% confidence interval $[\mathrm{Cl}], 0.633-0.723)$. The area under the curve of SMAD3 was 0.715 (95\% Cl, 0.672-0.758).

fewer than 30 cases. We demonstrated significant positive correlation between serum TGF-ß1/SMAD3 levels and CAD based on 547 subjects.

There has been no study stratifying patients according to CAD severity. It is probable that the relevance of TGF- $\beta 1$ in CAD can only be detected in severe disease, or high concentrations of TGF- $\beta 1$ from severe CAD may have a paradoxical effect $[27,30,31]$.

In the correlation of TGF- $\beta 1$ and SMAD3 levels with the risk factors of CAD, TGF- $\beta 1$ is closely related to Lp (a) and uric acid, which both are considered to be markers of atherosclerosis, indicating that this cytokine may contribute to the establishment of CAD by regulating atherogenesis. SMAD3 levels correlated closely with blood glucose, implying that SMAD3 may influence CAD occurrence and the development of DM. Interestingly, it has been reported that risk factors including Lp (a), uric acid, BUN, triglycerides, and ApoA1 can be useful biomarkers for different clinical diagnoses [21,32], but we found that TGF- $\beta 1$ and SMAD3 were more sensitive biomarkers for $\mathrm{CAD}$ than those factors mentioned above.

\section{Conclusion}

Serum TGF- $\beta 1$ and SMAD3 levels are closely associated with $\mathrm{CAD}$. The underlying mechanism may be their regulatory effects on atherosclerosis and blood sugar.
A limitation of the present study is that the control population differs from the cases, in terms of age and cardiovascular risk factors. The mean age difference ( $\sim 5$ years) should be acceptable in an epidemiologic study of CAD according to a previous report $[6,9]$. CAD predominates in an older population.

\section{Competing interests}

The authors had no conflicts of interest to declare in relation to this article.

\section{Authors' contributions}

WL and CC performed the study and wrote the manuscript. WC, JZ, and WL performed the study and/or contributed to data analysis and interpretation. $X G, B L$, and HW reviewed/approved the research protocol. $\mathrm{CH}$ takes full responsibility for the work as a whole, including the study design, access to data, and the decision to submit and publish the manuscript. All authors read and approved the final manuscript.

\section{Acknowledgments}

This paper was supported by the Doctor Scientific Research Foundation in Guangdong Medical College (no. 10201B01202 and XB1322) and the Natural Science Foundation of Guangdong Province (S2013040012115 and S2013010015074) and the National Natural Science Foundation of China (no. 81270212 and no. 81300035).

\section{Author details}

'Department of Cardiovascular Medicine, Renmin Hospital of Wuhan University, Wuhan 430060, China. ${ }^{2}$ Department of Cardiovascular Medicine, The Affiliated Hospital of Guangdong Medical College, Zhanjiang 524000, China.

Received: 23 October 2013 Accepted: 11 February 2014 Published: 17 February 2014 


\section{References}

1. Lloyd-Jones D, Adams R, Carnethon M, De Simone G, Ferguson TB, Flegal K, Ford E, Furie K, Go A, Greenlund K, Haase N, Hailpern S, Ho M, Howard V, Kissela B, Kittner S, Lackland D, Lisabeth L, Marelli A, McDermott M, Meigs J, Mozaffarian D, Nichol G, O'Donnell C, Roger V, Rosamond W, Sacco R, Sorlie P, Stafford R, Steinberger J, et al: American Heart Association Statistics Committee and Stroke Statistics Subcommittee. Heart disease and stroke statistics-2009 update: a report from the American Heart Association Statistics Committee and Stroke Statistics Subcommittee. Circulation 2009, 119:480-486.

2. Minino AM: Death in the United States, 2009. NCHS Data Brief 2011, 64:1-8.

3. World Health Organization Cardiovascular Diseases (CVDs): Who Fact Sheet. ; 2011.

4. Kathiresan S, Srivastava D: Genetics of human cardiovascular disease. Cell 2012, 148:1242-1257.

5. Stylianou IM, Bauer RC, Reilly MP, Rader DJ: Genetic basis of atherosclerosis: insights from mice and humans. Circ Res 2012, 110:337-355.

6. Tayebi N, Ke T, Foo JN, Friedlander Y, Liu J, Heng CK: Association of single nucleotide polymorphism rs6903956 on chromosome 6p24.1 with coronary artery disease and lipid levels in different ethnic groups of the Singaporean population. Clin Biochem 2013, 46:755-759.

7. Sugamura K, Keaney JF Jr: Reactive oxygen species in cardiovascular disease. Free Radic Biol Med 2011, 51:978-992.

8. Tousoulis D, Kampoli AM, Papageorgiou N, Androulakis E, Antoniades C, Toutouzas K, Stefanadis C: Pathophysiology of atherosclerosis: the role of inflammation. Curr Pharm Des 2011, 17:4089-4110.

9. Schaan BD, Quadros AS, Sarmento-Leite R, De Lucca G, Jr BA, Bertoluci M: 'Correction:' Serum transforming growth factor beta-1 (TGF-beta-1) levels in diabetic patients are not associated with pre-existent coronary artery disease. Cardiovasc Diabetol 2007, 6:19.

10. Grainger DJ: TGF-beta and atherosclerosis in man. Cardiovasc Res 2007, 74:213-222.

11. Bakin AV, Tomlinson AK, Bhowmick NA, Moses HL, Arteaga CL: Phosphatidylinositol 3-kinase function is required for transforming growth factor beta-mediated epithelial to mesenchymal transition and cell migration. J Biol Chem 2000, 275:36803-36810

12. Caraci F, Battaglia G, Busceti C, Biagioni F, Mastroiacovo F, Bosco P, Drago F, Nicoletti F, Sortino MA, Copani A: TGF-beta 1 protects against Abeta-neurotoxicity via the phosphatidylinositol-3-kinase pathway. Neurobiol Dis 2008, 30:234-242.

13. Edlin RS, Tsai S, Yamanouchi D, Wang C, Liu B, Kent KC: Characterization of primary and restenotic atherosclerotic plaque from the superficial femoral artery: potential role of Smad3 in regulation of SMC proliferation. J Vasc Surg 2009, 49:1289-1295.

14. Miyazawa K, Shinozaki M, Hara T, Furuya T, Miyazono K: Two major Smad pathways in TGF- superfamily signalling. Genes Cell 2002, 7:1191-1204.

15. Xu F, Lin SH, Yang YZ, Guo R, Cao J, Liu Q: The effect of curcumin on sepsis-induced acute lung injury in a rat model through the inhibition of the TGF-B1/SMAD3 pathway. Int Immunopharmacol 2013, 16:1-6.

16. Derynck R, Zhang YE: Smad-dependent and Smad-independent pathways in TGF-beta family signalling. Nature 2003, 425:577-584.

17. Zhu Y, Culmsee C, Klumpp S, Krieglstein J: Neuroprotection by transforming growth factor-beta1 involves activation of nuclear factor-kappaB through phosphatidylinositol-3-OH kinase/Akt and mitogen-activated protein kinase-extracellular-signal regulated kinase1,2 signaling pathways. Neuroscience 2004, 123:806-897.

18. Goel SA, Guo LW, Shi XD, Kundi R, Sovinski G, Seedial S, Liu B, Kent KC: Preferential secretion of collagen type 3 versus type 1 from adventitial fibroblasts stimulated by TGF- $\beta /$ Smad3-treated medial smooth muscle cells. Cell Signal 2013, 25:9559-9560.

19. Dobaczewski M, Chen W, Frangogiannis NG: Transforming growth factor (TGF)- $\beta$ signaling in cardiac remodeling. J Mol Cell Cardiol 2011, 51:600-606.

20. Bujak M, Frangogiannis NG: The role of TGF-beta signaling in myocardial infarction and cardiac remodeling. Cardiovasc Res 2007, 74:184-195.

21. Liu B, Zhang YM: Study on risk factors of premature coronary artery disease. Chin J Cardiovasc Res 2009, 7:629-632.

22. Lin WT, Wu XN, Zhu PP, Zhang ZF, Chen J: Studies on anti-tumor activities of enteromorpha chlorella growth factor in experimental liver cancer and its mechanism. J Fujian Med Univ 2009, 43:227-230.

23. Grainger DJ, Kemp PR, Metcalfe JC, Liu AC, Lawn RM, Williams NR, Grace AA, Schofield PM, Chauhan A: The serum concentration of active transforming growth factor-beta is severely depressed in advanced atherosclerosis. Nat Med 1995, 1:74-79.

24. Crook R, Leatham EW, Salomone OA, Hossein-Nia M, Grainger DJ, Kaski JC: Plasma levels of active transforming growth factor-beta are reduced in patients with three vessel coronary artery disease. Heart 1996, 75:79

25. Tashiro H, Shimokawa H, Yamamoto K, Momohara M, Tada H, Takeshita A: Altered plasma levels of cytokines in patients with ischemic heart disease. Coron Artery Dis 1997, 8:143-147.

26. Li CG, Bethell H, Wilson PB, Bhatnagar D, Walker MG, Kumar S: The significance of CD105, TGFbeta and CD105/TGFbeta complexes in coronary artery disease. Atherosclerosis 2000, 152:249-256.

27. Batuman O, Go D, Clark LT, Smith EL, Clements P, Feit A, Lederer D: Relationship between cytokine levels and coronary artery disease in women. Heart Dis 2001, 3:80-84.

28. Border WA, Ruoslahti E: Transforming growth factor-beta in disease: the dark side of tissue repair. J Clin Invest 1992, 90:1-7.

29. Tashiro H, Shimokawa H, Sadamatu K, Yamamoto K: Prognostic significance of plasma concentrations of transforming growth factor-beta in patients with coronary artery disease. Coron Artery Dis 2002, 13:139-143.

30. Stefoni S, Cianciolo G, Donati G, Dormi A, Silvestri MG, Coli L, De Pascalis A, lannelli S: Low TGF-beta1 serum levels are a risk factor for atherosclerosis disease in ESRD patients. Kidney Int 2002, 61:324-335.

31. Os I, Djurovic S, Seljeflot I, Berg K: Transforming growth factor (TGF)-beta1 inversely related to vascular cell adhesion molecule-1 in postmenopausal women with coronary artery disease. A possible mechanism for the putative cardioprotective role of TGF-beta1? J Intern Med 2002, 251:223-227.

32. Wen HH, Bai P, Niu L, Li YD: The influence of serum uric acid on acute myocardial infarction and its predicative value. Acta Acad Med Nei Mongol 2006, 28:27-31.

doi:10.1186/1471-2261-14-18

Cite this article as: Chen et al:: Serum TGF- $\beta 1$ and SMAD3 levels are closely associated with coronary artery disease. BMC Cardiovascular Disorders 2014 14:18.

\section{Submit your next manuscript to BioMed Central and take full advantage of:}

- Convenient online submission

- Thorough peer review

- No space constraints or color figure charges

- Immediate publication on acceptance

- Inclusion in PubMed, CAS, Scopus and Google Scholar

- Research which is freely available for redistribution 